ORIGINAL ARTICLE

\title{
Parent's satisfaction with the observance of "Patient Rights Charter" for children admitted to hospitals in Golestan province during 2018
}

\author{
ATEFEH HAGHPARAST ${ }^{1}$, ELHAM KHALOOBAGHERI ${ }^{* 2}$, RAHELE YOUSEFZADEH ${ }^{3}$, MALIHE KABUS ${ }^{4}$, RAZIYE \\ MAZROEI ${ }^{5}$ \\ ${ }^{1}$ MSc in Community Health Nursing, Ghaemshahr Health Network, Deputy of Health ,Mazandaran University of Medical Sciences, Sari, \\ Iran.mja.haghparast@yahoo.com; https://orcid.org/0000-0001-9823-7994Introduction \\ ${ }^{2}$ Master of Internal Surgery, Ali Ibn Abitaleb Hospital Rafsanjan University of Medical Sciences, Iran \\ ${ }^{3}$ Young Researchers and Elite Club, Aliabad Katoul Branch, Islamic Azad University, Aliabad Katoul, Iran \\ ${ }^{4}$ Young Researchers and Elite Club, Aliabad Katoul Branch, Islamic Azad University, Aliabad Katoul, Iran \\ ${ }^{5}$ Department of Nursing, Mashhad Branch, Mashhad University Of Medical Sciences, Mashhad, Iran. \\ Correspondence to: "Elham Khaloobagheri, Master of Internal Surgery, Ali Ibn Abitaleb Hospital Rafsanjan University of Medical Sciences, \\ Iran
}

\begin{abstract}
Background: Patient rights are the duties that medical staffs are required to perform for patients from the time of admission. The increasing attention of organizations to this issue has led to the creation of a charter called the "Charter of Patient Rights". Also, since children are a vulnerable group in society, these rights are more important to them. Therefore, this study was conducted to investigate the parents' satisfaction with the observance of patient rights charter for children admitted to children hospitals in Golestan province during 2018.

Methods: This cross-sectional and descriptive study was performed on 350 children admitted to hospitals of Golestan province. Sampling was done by convenience method. The data collection tool was the questionnaire of patient rights charter for hospitalized children. Data were analyzed by SPSS-18 statistical software using descriptive (frequency, mean and standard deviation) and inferential statistics (independent t-test and analysis of variance).

Results: The results showed that, the highest percentage of samples $73.4 \%$ (259 people) had moderate satisfaction and $26 \%$ of them (91 people) had high satisfaction with the observance of patient rights charter for children. The highest dissatisfaction was related to the laboratory tests and diagnostic procedures, so that only $68.3 \%$ of the samples (239 people) were satisfied with the response of staff and physicians and $11.1 \%$ of them (39 people) were dissatisfied with it. The highest level of satisfaction was related to the access to nurses during hospitalization, so that $86.9 \%$ of the samples (306 people) were satisfied and only $2.3 \%$ ( 8 people) were dissatisfied with it.

Conclusion: The results showed that a large number of parents were moderately satisfied with the observance of patient rights charter for children by staff. Since the observance of "Patient Rights Charter", in addition to the patient's satisfaction, shows the professionalism of medical staff, this charter must be implemented in the best way at all levels of health care and treatment.
\end{abstract}

Key words: Parental Satisfaction, Patient Rights Charter

\section{INTRODUCTION}

Observance of human rights in today's society is an undeniable principle [1]. The increasing attention of organizations to this issue has caused many countries to consider specific rights for patients in their health system [2]. Patient rights are the patient's expectations and needs that have been set in the form of specific standards and laws [3]. According to the definition of World Health Organization, patient rights are the rights that patients have, and service providers are obliged to implement them [4]. In order to ensure the observance of these standards and laws, health systems have considered a charter called the "Patient Rights Charter" for all family members, especially hospitalized children [5]. For this purpose, in April 1959, the United Nations signed the "Charter of Children Rights", to ensure children are provided with the best and high quality services that include healthy water, nutritional food, healthy and safe environment, and provision of accurate information [6]. Obviously, respecting patient rights increases their sense of security and satisfaction, and this in turn increases the patient's and his family's participation in treatment, which reduces the length of hospital stay, treatment costs, and recovery time [4].
Usually in hospitals, parents play the role of primary caregiver and are an integral part of the child care, so their satisfaction affects the satisfaction of children [7]. Satisfaction of children and their parents reflects the ability of physicians and treatment team and shows the quality of services they provide. Also, from the perspective of the World Health Organization, patient satisfaction is one of the five indicators of service quality [8]. Dissatisfaction leads to reduced cooperation, wasted resources, and negative health outcomes [9]. Many studies have been conducted on the observance of the charter of older patient rights. According to the study conducted in Gonabad, the observance of patient rights charter was reported at $69.1 \%$ [10]. The results of Arab et al study showed the observance of patient rights charter at $82.9 \%$ [11]. Since 2000, more studies have been conducted on the observance of patient rights charter for children. According to the research conducted by Ulus and Kublai, the level of parents' satisfaction with the observance of their children's rights was reported at $62.55 \%$ [12]. Another study showed that providing counseling about treatment methods will increase the satisfaction of both parents and the sick children [13]. The study of Krish et al, revealed that parents were 
dissatisfied with the observance of patient rights charter for their children, and also most of the dissatisfactions were related to the lack of explanation about medical diagnoses, use of medical terms and lack of proper communication [14]. In order to enforce the rights of children and emphasize on the importance of this issue, the World Health Organization has introduced programs, in which all service providers are required to comply with these laws. Since the observance of patient rights charter reflects the ability of physicians and treatment team and quality of services they provide, and non-compliance with it reduces the satisfaction of service users and quality of care, the researcher decided to conducted a study to determine the level of parental satisfaction with the observance of patient rights charter for children admitted to hospitals in Golestan province.

\section{METHODS AND MATERIALS}

This is a cross-sectional and descriptive study that was conducted on children admitted to specialized pediatric hospitals in Golestan province during 2018. The environment of this study was Taleghani Pediatric Hospitals in Gorgan and Gonbad Kavous. The criteria for entering the study included the parents of children who have been hospitalized in the pediatric ward on the doctor's orders for at least three days. Exclusion criteria included the children who have been admitted to the emergency department or outpatient clinic of the hospitals. The sample size of this study was calculated to be 250 individuals according to the study of Ardakan et al. (2015) with a test power of $80 \%$ and an error of 0.1 at the significance level of $0.05[5]$.

Data collection tools included a demographic characteristics questionnaire and a questionnaire for observing the charter of patient rights for children hospitalized by the health care team. This questionnaire had 22 questions in three-option scales of satisfied (score 1 ), somewhat satisfied (score 2) and dissatisfied (score 2). Lower scores indicated greater satisfaction with compliance with the charter of children rights. This questionnaire was approved in the study of Ardakan et al. with the Cornbach's alpha of 0.87 . Also, the validity of this questionnaire was confirmed by ten faculty members of Islamic Azad University and University of Medical Sciences. The reliability of this questionnaire was confirmed with the Cronbach's alpha coefficient of 0.82 . The ethics committee of Islamic Azad University of Chalous, approved this project with the code: IR.IAU.CHALUS.REC.1395.24. Then, the researcher attended the hospitals and obtained permission from hospital and ward officials. An explanation about the objectives of study, confidentially of information and principle of anonymity was given to the participants. Data was collected by self-reporting method. The researcher was present with the participants while they completed the questionnaire and answered their questions. The participants completed the questionnaire during the visiting time at the visiting room, which took 10-15 minutes for each questionnaire. Data were collected and then analyzed by SPSS-16 statistical software using descriptive (table, mean, standard deviation) and inferential statistics (independent $t$ and types) at a significant level of 0.05 .

\section{RESULTS AND DISCUSSION}

The mean age of hospitalized children was $4.02 \pm 2.02$ years, with the highest percentage $52.9 \%$ (185 people) being girls and $47.1 \%$ (165 people) being boys, of whom $51.7 \%$ (181 people) had a history of hospitalization and $48.3 \%$ (169 people) had no history of hospitalization. The highest percentage of consent form $88 \%$ (308 people) was completed by the mothers and the lowest percentage $12 \%$ (42 people) was completed by the fathers. In terms of education, $47 \%$ (265 people) of parents had under diploma education, 29.7\% (104 people) had diploma, and 23.7 (81 people) had university education.

The results of present study showed that, the observance of patient rights charter was $27.4 \pm 5.7$. The highest percentage of samples $74 \%$ (259 people) had moderate satisfaction and $26 \%$ (91 people) had high satisfaction with the observance of patient rights charter for children.

Table 1: The level of observance of patient rights charter for hospitalized children by hospital staff from the perspective of parents

\begin{tabular}{|c|c|c|c|c|c|}
\hline & \multirow[t]{2}{*}{ Question } & \multirow[t]{2}{*}{ Mean + SD } & \multicolumn{3}{|c|}{ Observance of patient rights charter for children } \\
\hline & & & Satisfied & Somewhat satisfied & Dissatisfied \\
\hline 1 & Access to a doctor during hospitalization & $1.4 \pm 0.73$ & $261(74 \%)$ & $37(11 \%)$ & $52(15 \%)$ \\
\hline 2 & Access to the nurse during the hospitalization & $1.16 \pm 0.43$ & $304(83 \%)$ & $36(10 \%)$ & $10(3 \%)$ \\
\hline 3 & Respectful behavior of employees & $1.18 \pm 0.42$ & $291(83 \%)$ & $54(16 \%)$ & $3(1 \%)$ \\
\hline 4 & Keeping file information confidential & $1.17 \pm 0.43$ & $295(84 \%)$ & $48(14 \%)$ & $7(2 \%)$ \\
\hline 5 & Allowing the child to be taken with personal consent & $1.21 \pm 0.45$ & $280(80 \%)$ & $64(18 \%)$ & $3(1 \%)$ \\
\hline 6 & Providing information about the diagnosis & $1.37 \pm 0.65$ & $252(72 \%)$ & $65(19 \%)$ & $33(10 \%)$ \\
\hline 7 & Treating and providing care as soon as possible & $1.35 \pm 0.66$ & $261(74 \%)$ & $53(16 \%)$ & $36(10 \%)$ \\
\hline 8 & Obtaining consent for research work & $1.1 \pm 0.37$ & $222(92 \%)$ & $20(6 \%)$ & $9(2 \%)$ \\
\hline 9 & Explanation about the test and personal work & $1.42 \pm 0.68$ & $240(69 \%)$ & $71(20 \%)$ & $39(11 \%)$ \\
\hline 10 & Information on treatment method & $1.24 \pm 0.52$ & $279(80 \%)$ & $56(16 \%)$ & $15(4 \%)$ \\
\hline 11 & Talk about the complications of the disease & $1.21 \pm 0.42$ & $267(76 \%)$ & $83(25 \%)$ & 1 I \\
\hline 12 & Talk about the prognosis of the disease & $1.33 \pm 0.63$ & $267(76 \%)$ & $52(15 \%)$ & $31(9 \%)$ \\
\hline 13 & Helping the patient regardless of culture and ethnicity & $1.32 \pm 0.63$ & $263(75 \%)$ & $81(23 \%)$ & $3(2 \%)$ \\
\hline 14 & Provide a complete description of the disease & $1.2 \pm 0.47$ & $285(81 \%)$ & $57(16 \%)$ & $8(2 \%)$ \\
\hline 15 & Provide adequate explanations about the treatment process & $1.17 \pm 0.43$ & $295(84 \%)$ & $48(14 \%)$ & $7(2 \%)$ \\
\hline 16 & Introducing social and welfare support centers & $1.25 \pm 0.48$ & $267(76 \%)$ & $76(21 \%)$ & $7(2 \%)$ \\
\hline 17 & Familiarity of the patient with the hospital environment at admission & $1.214 \pm 0.43$ & $278(70 \%)$ & $68(19 \%)$ & $4(1 \%)$ \\
\hline 18 & Obtain consent for the laboratory procedure & $1.19 \pm 0.41$ & $295(84 \%)$ & $42(12 \%)$ & $13(4 \%)$ \\
\hline 19 & Provide information on the ward's regulations & $1.2 \pm 0.49$ & $280(80 \%)$ & $58(16 \%)$ & $7(2 \%)$ \\
\hline 20 & Introducing the staff nurse at admission & $1.21 \pm 0.44$ & $287(82 \%)$ & $56(16 \%)$ & $7(2 \%)$ \\
\hline 21 & Introducing the doctor at admission & $1.12 \pm 0.32$ & $307(88 \%)$ & $43(12 \%)$ & \\
\hline 22 & Provide information on hospital tariffs & $1.27 \pm 0.51$ & $262(75 \%)$ & $79(22 \%)$ & $9(3 \%)$ \\
\hline
\end{tabular}


In the Children Rights Questionnaire, the most dissatisfaction was related to question (9) that was related to the necessary explanations about tests and diagnostic procedures, of which only $68.3 \%$ (239 people) of the samples were satisfied with the response of staff and physicians and $11.1 \%$ (39 people) of them were dissatisfied with it. Also, the most dissatisfaction was related to question (1) that was about the access to physicians during hospitalization, of which only $74.6 \%$ (261 people) of the samples were satisfied with it, and $14.9 \%$ (52 people) of them were dissatisfied with it. The highest level of satisfaction was related to question (2) that was about access to nurses during hospitalization, of which $86.9 \%$
(304 people) of the samples were satisfied with it and only $2.3 \%$ (8 people) were dissatisfied. In relation to question (21) that was about introduction of pediatric physician to parents and their child, $85.1 \%$ (208) of the samples were satisfied and $2.9 \%$ (10) were dissatisfied with it (Table 1). The independent t-test showed a statistical difference between the observance of children rights charter $(p=$ $0.25)$, parental ratio $(p=0.57)$, place of residence $(p=0.6)$, gender $(p=0.79)$, history of hospitalization $(p=0.4)$, and parents' occupation $(p=0.84)$. The analysis of variance did not show a significant difference between the parents' literacy levels.

Table 2: Relationship between compliance with the Charter of Patient Rights for Children and demographic characteristics

\begin{tabular}{|c|c|c|c|c|}
\hline Observance of the charter & & & Mean + SD & P-value \\
\hline \multicolumn{3}{|l|}{ Demographic } & & \\
\hline \multirow[t]{2}{*}{ Gender } & Girl & 185 & $27.52 \pm 5.95$ & \multirow[t]{2}{*}{$\mathrm{P}=0.73$} \\
\hline & Boy & 165 & $27.31 \pm 5.18$ & \\
\hline \multirow[t]{2}{*}{ History of hospitalization } & Yes & 181 & $27.38 \pm 5.91$ & \multirow[t]{2}{*}{$\mathrm{P}=0.9$} \\
\hline & No & 169 & $27.41 \pm 5.51$ & \\
\hline \multirow[t]{2}{*}{ Parents' ratio } & Father & 42 & $27.43 \pm 5.55$ & \multirow[t]{2}{*}{$\mathrm{P}=0.23$} \\
\hline & Mother & 308 & $27.28 \pm 6.53$ & \\
\hline \multirow[t]{4}{*}{ Parents' education level } & Illiterate & 49 & $26.36 \pm 5.62$ & \multirow{4}{*}{$P=0.38$} \\
\hline & Secondary & 116 & $27.87 \pm 5.35$ & \\
\hline & Diploma & 104 & $27.11 \pm 5.46$ & \\
\hline & University & 81 & $27.79 \pm 6.92$ & \\
\hline
\end{tabular}

This study was conducted to determine the relationship between the observance of patient rights charter for children and parents' satisfaction during 2018.

According to the findings of this study, a large number of parents were moderately satisfied with observance of patient rights charter for children by medical staff. The highest percentage of samples $73.4 \%$ (259 people) had moderate satisfaction and $26 \%$ (91 people) had high level of satisfaction with the observance of patient rights charter for children. A study conducted by Kublai and Ulus with the aim of assessing parental satisfaction and anxiety for children hospitalized in 2019 also showed that parental satisfaction score was 62.55 that was at moderate level. According to the findings of present study, the highest level of satisfaction was related to the access to nurses during hospitalization, of which $86.9 \%$ (306 people) of the samples were satisfied with it. The results of a study by Jordan et al., showed that communication and providing appropriate information can have a positive effect on parental satisfaction [12]. However, Daniel et al., found the presence of parents with the child and consultation with them as the most important factors in increasing parental satisfaction [13]. Kublai and Ulus also found that, the lower mothers' anxiety, the higher their satisfaction [15]. In the present study, the highest dissatisfaction was related to the necessary explanations about tests and diagnostic procedures, of which $68.3 \%$ of the samples were satisfied with the response of staff and physicians and only $11.1 \%$ were dissatisfied with it. In the study of Krish et al., parents' dissatisfaction was due to lack of explanation about diagnoses, the use of medical terms and inappropriate communication. Dissatisfaction with the lack of necessary explanations regarding the diagnostic procedures is consistent with the results of our study [14]. In a study by Joibari et al., conducted in Iran, $70 \%$ of parents were aware of and complied with the children rights charter, and parents' satisfaction with children rights charter was high [16].

However, in his study, Wecher referred to the lack of privacy in the hospital as the worst experience of patients in the hospital and considered it as one of the main factor in patient dissatisfaction, which is not in line with the results of our study [17]. Increasing awareness about the compliance with patient rights charter increases patient understanding of health services and reduces stress and dissatisfaction with medical services at the time of hospitalization [18]. Because according to studies, receiving sufficient information about the disease, the right of access to medical records and the right to be informed of the decisions made by the treatment team are among the patient rights [19]. When patients understand their rights, their participation in clinical decision-making and care plan increases [20].

In the study of Ardakani et al., the parents' dissatisfaction with the observance of children rights charter, was mainly due to the lack of introduction of nursing staff to parents, and lack of information and knowledge about support and insurance systems [5]. In the present study, the level of parents' satisfaction with the introduction of nurses at the start of hospitalization and rendering of information about support systems was high.

In general, observance of patient rights is one of the most important components of ethical care, and many studies in the world have been emphasizing on the importance of compliance with these rights. However, in order to observe these rights, it is necessary to provide the necessary training to nurses in order to increase their awareness about them [19]. In case of increasing awareness and information, people would be able to take care of themselves better [21]. Also, with the increase of 
awareness and involvement of parents in the care of hospitalized children, their level of stress and anxiety caused by hospitalization decreases [22].

In this study, there was no significant difference between the compliance with the Charter of Children Rights and demographic characteristics. In Baba Mohammadi et al (2011) study, there was no significant difference between the observance of patient rights charter and age, education, place of residence, and gender of the staff [23]. However, in the study of Joolaei et al, people with higher education had a greater understanding of patient rights, and this increased their awareness [24]. This increase in awareness could be due to the greater involvement of cultural issues and the level of parents' education, which were not examined in this study.

\section{CONCLUSION}

The results of this study showed that most parents were satisfied with the observance of patient rights charter for children during hospitalization. However, in some cases, such as access to physician, they expressed their dissatisfaction. Therefore, hospital managers and clinical staff can increase parental satisfaction and reduce concerns by holding additional training courses for physicians and nurses, as well as making the necessary arrangements for higher number of physicians to attend the ward. The ward managers can also alleviate the parents' worries by providing them with training and information brochures on treatment process, hospital staff, insurance system, and any other necessary explanations at the time of admission.

Author's contribution: All authors contributed for preparing and finalization of this article.

Acknowledgement: This project was approved by the Student Research Committee of the Faculty of Medical Sciences at the Islamic Azad University, Aliabad Katoul Branch. The authors would like to thank all those who helped us to conduct this study.

Funding: We have no funding source for this project.

Declaration of Conflicting Interests: All the authors declare that there is no conflict of interest for this project

Data availability: The data that support the findings of this study are available from the corresponding author, upon reasonable request.

\section{REFERENCES}

1. Kalhor M, Kaveii B, Samiee-Rad F. Evaluating Patients awareness and satisfaction of implementing Patients' Rights Charter at Kowsar Hospital in Qazvin. gums-rme. 2017;9(3):37-29.

2. Joolaee $\mathrm{S}$, Hajibabaee $\mathrm{F}$. Patient rights in Iran: a review article. Nursing ethics. 2012;19(1):45-57

3. Jadidi A, Safarabadi M, Pourandish Y, Irannejad B. The Relationship between educational level and the Emergency Medical Services (EMS) staff quality of performance in dealing with cardiac arrest patients from the perspective of patients' rights. ethic. 2016;5(2):33-8.

4. Jooj $R$, Hajibabaee $F$, Zarea $K$, HAGHIGHIZADEH $M$ RELATIONSHIP BETWEEN AWARENESS OF AND RESPECT FOR PATIENTS'RIGHTS FROM THE PERSPECTIVE OF PATIENTS ADMITTED TO PSYCHIATRIC WARDS. 2015.

5. Mahboobi Ardakan $P$, Shafie Mazrae no $H$, Zarezadeh $M$ Shaterzadeh F, mehdizadeh P, motaghed Z, et al. Parent satisfaction rate of the patient bill of rights application status for children's admitted in pediatric educational and treatment Centers affiliated to Tehran University of Medical Sciences. Sci-J-Forensic-Med. 2015;20(4):221-9

6. Przybylska MA, Burke N, Harris C, Kazmierczyk M, Kenton E, Yu O, et al. Delivery of the UN Convention on the Rights of the Child in an acute paediatric setting: an audit of information available and service gap analysis. BMJ paediatrics open. 2019;3(1).

7. David Vainberg $L$, Vardi A, Jacoby $R$. The Experiences of Parents of Children Undergoing Surgery for Congenital Heart Defects: A Holistic Model of Care. Frontiers in Psychology. 2019;10:2666.

8. Geletta S. Measuring patient satisfaction with medical services using social media generated data. International journal of health care quality assurance. 2018;31(2):96-105.

9. Ravaghi H, Gohari M, D Marellelu A, Mehrtak M, Jafari Oori M, Azari A, et al. Assessing the Inpatients Awareness from Patients Rights and Their Satisfaction from Observance of That Rights in the General-Educational Hospitals of Tehran University of Medical Sciences. Journal of Health. 2016;7(1):26-34.

10. Basiri Moghadam K, Basiri Moghadam M, Moslem A, Ajam Zibad H, Jamal F. Health Providers and Patients' Awarness on Patient Bill of Rights and Its Observing Rate in 22 Bahman Hospital. QHMS. 2011;17(1):45-54.

11. Arab M, Zarei A, Hosseini M. Awareness and observation of patients rights from the perspective of patients: a study in university hospitals in Tehran. sjsph. 2010;8(2):77-86.

12. Yılmaz G, Küçük Alemdar D. Sources of Anxiety and Satisfaction Level of the Mothers Whose Children Hospitalized for Acute Reasons. Journal of Client-Centered Nursing Care. 2019:5(1):63-70.

13. Yolme ABS, Hojjati H, Akhoundzadeh G. The effect of Islamic semanticism on self-reporting and lifestyles of mothers of adolescents with thalassemia. International Journal of Adolescent Medicine and Health. 2020 Feb. DOI: 10.1515/ijamh-2019-0192.

14. Salehi Z, Mokhtari Nouri J, Khademolhoseini M, Ebadi A. Survey of parents Satisfaction of infants admitted in the NICU. Iran J Crit Care Nurs. 2015;7(4):245-52.

15. Moghaddam MN, Amiresmaeili M, Ghorbaninia R, Sharifi T, Tabatabaie SS. Awareness of Patients' rights charter and respecting it from the perspective of patients and nurses: A study of limited surgical centers in Kerman city, 2013. Bioethics Journal. 2016;4(11):31-56.

16. Jouybari L, Sanagoo A, Bibi Soltani A. Viewpoints of Middle-School Students of Gorgan About Respecting the Children's Rights by their Parents. RUMS_JOURNAL. 2011;10(3):193-204.

17. Tabarsa, M. ., Roshangaran, F. ., fakhreazizi, S. ., Khaloobagheri, E . \& Hekmati Pour, N. (2021). The Effect of Extended Parallel Process Model on Sexual Self- Control of Female Adolescents in Aliabad Kotoul in 2020. Indian Journal of Forensic Medicine \& Toxicology, 15(3), 495-499. https://doi.org/10.37506/ijfmt.v15i3.15352

18. Hosseini N, Akhoundzadeh $\mathrm{G}$, Hojiati $\mathrm{H}$. The effect of child-parent relationship therapy on social skills of Preschool Children: a semiexperimental study. International Journal of Adolescent Medicine and Health. 2019. DOI: 10.1515/ijamh-2019-0151

19. Rooeintan M, Haghighi S, Sakimaleh M. Assess the Educational Needs of Nurses to Patient's Charter of Rights in Ahwaz Teaching Hospitals (1392-93). muk-zanko. 2018;19(61):85-94.

20. Mahlagha D, Roghayeh M, Masoud R, Mohammad Z, Mina M, Maryam I, et al. Comparison of the importance and observance of the patient's bill of rights from the perspectives of patients and personnel of hospitals in Kerman. Journal of Medical Ethics and History of Medicine. 2020;13(0)

21. Nafiseh HP, Mahmoodi-Shan GR, Abas E, Naser B. Spiritual selfcare in adolescents: a qualitative study. Int J Adolesc Med Health. 2020.

22. Hanieh Sajadi GAHH. The Effect of Empowerment Program on Participation of Mothers with Premature Infants Hospitalized in Neonatal Intensive Care Unit of Sayyed Shirazi Hospital in Gorgan, in 2018. Indian Journal of Forensic Medicine \&amp; Toxicology. 2020;14(2):1269-76.

23. Babamahmoodi $F$, Meftahi $M$, Khademloo $M$, Hesamzadeh A Observation of patient's right charter in Mazandaran teaching hospitals: patients view. ijme. 2011;4(4):37-44.

24. Joolaee S, Hajibabaee F, Jafar Jalal E, Bahrani N. Assessment of Patient Satisfaction from Nursing Care in Hospitals of Iran University of Medical Sciences. tums-hayat. 2011;17(1):35-44. 